\title{
Impaired Recognition Memory on the Doors and People Test After Damage Limited to the Hippocampal Region
}

\author{
Joseph R. Manns ${ }^{1}$ and Larry R. Squire ${ }^{2 *}$ \\ ${ }^{1}$ Department of Psychology, University of California, \\ San Diego, San Diego, California \\ ${ }^{2}$ Veterans Affairs Medical Center, San Diego, \\ and Departments of Psychiatry, Neuroscience, \\ and Psychology, University of California, San Diego, \\ San Diego, California
}

\begin{abstract}
There have been conflicting reports about the importance of the hippocampal region for recognition memory. Vargha-Khadem et al. (1997) described three patients who became amnesic early in life as a result of damage apparently limited to the hippocampal region. One of these patients (Jon) performed normally on the recognition portion of the Doors and People Test but was severely impaired in recall. To compare adult-onset amnesia directly with these early-onset cases, we tested six amnesic patients on the Doors and People Test. Three of the patients have damage thought to be limited to the hippocampal region. All six patients were markedly impaired on both the recall and recognition portions of the test. To account for the difference between our adult-onset cases and the early-onset case (Jon), we suggest that some compensation for Jon's injury occurred during development, either due to functional reorganization of cortex adjacent to the hippocampus or as the result of learned strategies. Hippocampus 1999;9:495-499. ๑1999 Wiley-Liss, Inc.
\end{abstract}

KEY WORDS: human; amnesia; declarative memory; medial temporal lobe; recall

\section{INTRODUCTION}

The capacity for recollecting facts and events depends on the integrity of medial temporal lobe and midline diencephalic structures (Schacter and Tulving, 1994; Squire and Zola, 1997; Gabrieli, 1998). A topic of recent interest concerns the status of recognition memory in patients with damage limited to the hippocampus or hippocampal formation. It has been proposed that the hippocampal region (the CA fields of the hippocampus proper, the dentate gyrus, and the subicular complex) is important for recollecting specific events but has a limited role in recognition memory (e.g., the capacity for judging familiarity) (Aggleton and Shaw, 1996;

Grant sponsor: Medical Research Service of the Department of Veterans Affairs; Grant sponsor: NIMH; Grant number: MH24600-26.

*Correspondence to: Larry R. Squire, Ph.D., Veterans Affairs Medical Center 116A, 3350 La Jolla Village Drive, San Diego, CA 92161. E-mail: Isquire@ ucsd.edu

Accepted for publication 27 May 1999
Vargha-Khadem et al., 1997, 1998; Aggleton and Brown, 1999). Another view is that the hippocampal region is important for recognition just as it is for other aspects of declarative memory (Haist et al., 1992; Reed and Squire, 1997; Zola and Squire, in press).

Recently, Vargha-Khadem et al. (1997) described three amnesic patients, all of whom developed memory impairment early in life as the result of damage apparently limited to the hippocampal region. One of the patients (Jon) was born prematurely, had convulsions at the age of 4 , and was noted to have memory impairment within 1.5 years after the convulsions. Jon was evaluated as a young adult on the Doors and People Test (Baddeley et al., 1994), a test that includes standardized subtests for both recognition and recall. He scored above the 50th percentile for recognition but below the 1st percentile for recall (Vargha-Khadem et al., 1998). Because the contrast between Jon's good recognition performance and his impaired recall is so striking, we assessed six amnesic patients on the same test. All six patients developed amnesia in adulthood, and three of them have bilateral damage thought to be limited to the hippocampal region.

\section{MATERIALS AND METHODS}

\section{Participants}

\section{Amnesic patients}

Of the amnesic patients who participated (see Tables 1 and 2), two have bilateral hippocampal damage identified by magnetic resonance imaging (MRI). P.H. (Polich and Squire, 1993) had a 6-year history of 1- to 2-min- 
TABLE 1.

Characteristics of Amnesic Patients*

\begin{tabular}{lcccccccc}
\hline & & & & \multicolumn{5}{c}{ WMS-R Subtest } \\
\cline { 6 - 9 } Patient & $\begin{array}{c}\text { Age } \\
\text { (years) }\end{array}$ & Lesion & $\begin{array}{c}\text { WAIS-R } \\
\text { IQ }\end{array}$ & Attention & Verbal & Visual & General & Delay \\
\hline A.B. & 60 & HFa & 104 & 87 & 62 & 72 & 54 & $<50$ \\
L.J. & 60 & HF & 98 & 105 & 83 & 60 & 60 & $<50$ \\
P.H. & 76 & HF & 120 & 117 & 67 & 83 & 70 & 57 \\
P.N. & 70 & Dien & 99 & 81 & 77 & 73 & 67 & 53 \\
R.C. & 81 & Dien & 106 & 115 & 76 & 97 & 80 & 72 \\
J.W. & 61 & Dien & 98 & 104 & 65 & 70 & 57 & 57 \\
M & 68 & & 104.2 & 101.5 & 71.7 & 75.8 & 64.7 & 56.5 \\
\hline
\end{tabular}

${ }^{*}$ Note. The Wechsler Adult Intelligence Scale-Revised (WAIS-R) and the Wechsler Memory Scale-Revised (WMS-R) yield a mean score of 100 in the normal population, with a standard deviation of 15 . The WMS-R does not provide scores for individuals who score below 50 . Therefore, the two scores below 50 were scored as 50 for calculating a group mean. Dien, diencephalon; HF, hippocampal formation.

aAlthough the site of the lesion has not been confirmed radiologically, the etiology of the amnesia (anoxia) suggests that damage has occurred to the hippocampal formation.

ute "attacks" (with a possible epileptic basis) that were associated with gastric symptoms and transient memory impairment. In July of 1989, he suffered from a series of brief episodes after which he had a marked and persistent memory loss. Patient L.J. (Reed and Squire, 1998) became amnesic during a 6-month period beginning in 1988 with no known precipitating event. Her memory impairment has remained stable since that time. A third patient (A.B.) is unable to participate in magnetic resonance imaging studies. He became amnesic in 1976 after an anoxic episode after cardiopulmonary arrest and is presumed to have hippocampal

\section{TABLE 2.}

\section{Memory Test Performance*}

\begin{tabular}{lccccc}
\hline & & \multicolumn{3}{c}{ Paired associates } & \\
\cline { 3 - 5 } & Diagram & Trial & Trial & Trial & $\begin{array}{c}\text { Word } \\
\text { recall } \\
\text { Patient }\end{array}$ \\
\hline A.B. & 4 & 1 & 1 & 1 & 33 \\
L.J. & 3 & 0 & 0 & 0 & 40 \\
P.H. & 3 & 0 & 0 & 1 & 27 \\
P.N. & 2 & 1 & 1 & 1 & 29 \\
R.C. & 3 & 0 & 0 & 3 & 19 \\
J.W. & 4 & 0 & 0 & 2 & 28 \\
M & 3.2 & 0.3 & 0.3 & 1.3 & 29.3 \\
Control $M(\mathrm{n}=8)$ & 20.6 & 6.0 & 7.6 & 8.9 & 71.0 \\
\hline
\end{tabular}

${ }^{*}$ Note. The diagram recall score is based on the delayed (12 minute) reproduction of the Rey-Osterrieth figure (Osterrieth, 1944; maximum score $=36$ ). The paired associates score is the number of word pairs recalled on three successive trials (maximum score $=10$ per trial). The word recall score is the mean percentage of 15 recalled across five successive study-test trials (Rey, 1964). The mean scores for controls are from Squire and Shimamura (1986). damage on the basis of this etiology. Three other patients have alcoholic Korsakoffs syndrome (two men and one woman). All three had participated in an MRI study (Squire et al., 1990) that demonstrated marked reductions in the volume of the mammillary nuclei. Additionally, two patients (P.N. and J.W.) had participated in a computed tomography (CT) study (Shimamura et al., 1988) that revealed reduced thalamic tissue density and frontal lobe atrophy.

For all six patients, immediate and delayed (12-minute) recall of a short prose passage (Gilbert et al., 1968) averaged 4.8 and 0 segments, respectively (maximum number of segments, 21). They performed normally on the Boston Naming Test (Kaplan et al., 1983), achieving a mean score of 56.5 (maximum possible, 60; range, 55-58). They also performed well on the Dementia Rating Scale (Mattis, 1976), losing points primarily on the memory subportion. Their mean score was 131.3 (maximum possible, 144; range, 125-134), and they lost an average of 6.5 points on the Memory subportion. Scores for normal participants on the Boston Naming Test and the Dementia Rating Scale can be found elsewhere (Squire et al., 1990).

\section{Controls}

The controls (four men, two women) were volunteers or employees at the San Diego Veterans Affairs Medical Center who matched the amnesic patients with respect to age (see Table 1), education ( $M=14.8$ years vs. 14.2 years for the patients), and WAIS-R Information and Vocabulary subscale scores $(M s=20.5$ and 56.2, respectively, vs. 20.0 and 55.7 for the patients). Immediate and delayed recall of the short prose passage averaged 8.2 and 6.3 , respectively.

\section{Materials and Procedure}

The Doors and People Test was administered in the same way to all participants according to the published manual (Baddeley et 
al., 1994). It consists of four subtests: two that test recall and two that test recognition.

\section{Verbal recall (People test)}

Four pictures were presented for 3 seconds each. Each picture contained a photograph of a person together with a printed name and occupation. After viewing the fourth picture, participants were immediately asked to recall each name when cued by the occupation (e.g., "What is the name of the doctor?"). This procedure (presentation of four pictures and cued recall) was repeated a total of three times or until all four names could be recalled. Finally, delayed cued recall of the names was tested after the second subtest was given (about 8 minutes later).

\section{Visual recognition (Doors test)}

In the study phase, participants viewed photographs of 12 doors for 3 seconds each. Immediately thereafter, participants viewed 12 arrays of four doors each, and tried to identify the door from the study list. This same test was repeated with new photographs of doors, but with foils that were rather similar to the doors on the study list.

\section{Visual recall (Shapes test)}

Participants began by copying each of four simple line drawings, all of which resembled crosses. They then tried to draw the four shapes from memory. This same procedure was repeated a total of three times or until all four shapes were reconstructed correctly. For the second and third trials, participants viewed the shapes but did not copy them. Delayed recall of the shapes was tested after the fourth subtest was given (about 8 minutes later).

\section{Verbal recognition (Names Test)}

In the study phase, 12 female names (both a first name and a surname) were presented for 3 seconds each, and the participants read them aloud. Immediately thereafter, participants saw 12 lists of four names each and tried in each case to select the name from the study list. All four names in each group used the same first name and the same initial letter for the surname. This same test was then repeated with male names. In this case, the foils and the names from the study list differed only in one syllable of the surname.

\section{RESULTS}

Figure 1 shows the mean raw scores ( \pm SEM) for controls and amnesic patients on each of the four subtests. Table 3 shows the raw scores and percentile scores for each amnesic patient. The amnesic patients scored significantly lower than the controls on all four subtests ( $t$ s $[10]>2.81$, all $P_{s}<.02$ ). For each subtest, raw scores were converted to age-scaled scores and then to percentile scores according to tables in the test manual.

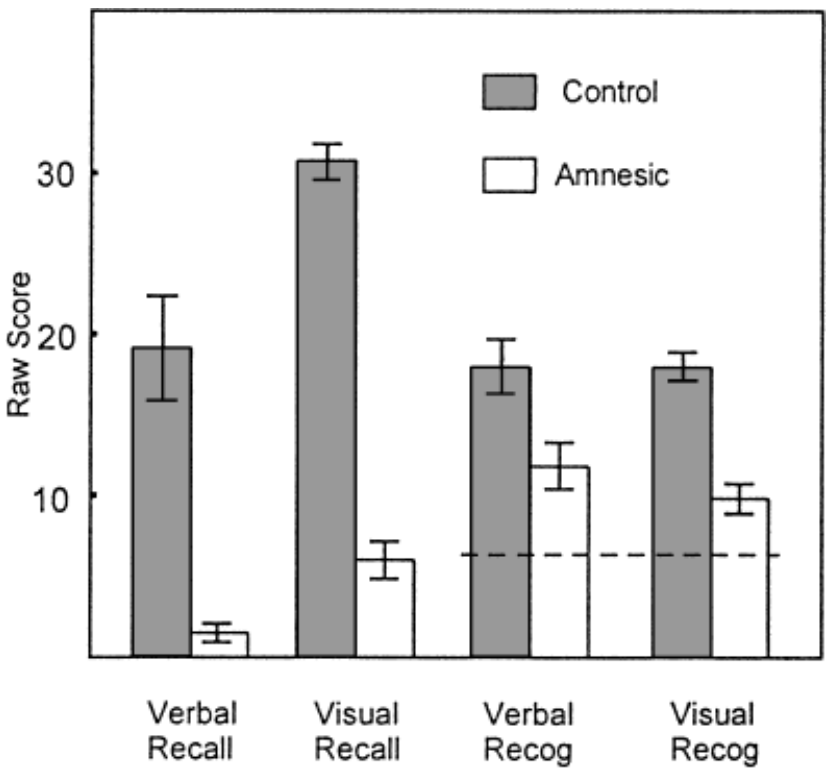

FIGURE 1. Mean raw scores for controls $(n=6)$ and amnesic patients $(n=6)$ on the four subtests of the Doors and People Test. The maximum score was 36 for each recall test and 24 for each recognition test. The dashed line represents chance performance (raw score $=6$ ) on the recognition tests. Brackets show SEM. Recog, recognition.

Many of the raw scores for the amnesic patients fell below the range for which the testing manual provides normative data for scaled scores. In these cases, the patient was assigned the lowest scaled score possible for each test. This procedure underestimates the severity of impairment, but inasmuch as most of the patients obtained percentile scores of 1.0 for both recall and recognition, the procedure had no significant impact on the results.

The test manual also derives a percentile score for both recognition and recall (Fig. 2). The percentile scores for the amnesic patients were significantly lower than the controls for both recall $(t(10)=2.78, P<.05)$ and recognition $(t(10)=4.28$, $P<.01)$. Finally, our controls obtained a recognition percentile score that was unexpectedly higher than their recall percentile score, even though the test is constructed to yield similar scores in the normal population. This finding may be attributable to the small number of controls $(n=6)$ that we tested.

\section{DISCUSSION}

Amnesic patients, including three with damage limited to the hippocampal region, were markedly impaired on the verbal and visual recognition subtests of the Doors and People Test. The finding that hippocampal damage impaired recognition memory argues against the suggestion that judgments of familiarity do not depend on the hippocampal region (Aggleton and Shaw, 1996; Aggleton and Brown, 1999). The results also differ with the conclusions reached by Vargha-Khadem et al. (1997) on the basis 
TABLE 3.

Scores of Amnesic Patients on the Doors and People Test*

\begin{tabular}{|c|c|c|c|c|c|c|}
\hline \multirow[b]{3}{*}{ Patient } & \multicolumn{4}{|c|}{ Raw scores } & \multirow{2}{*}{\multicolumn{2}{|c|}{ Percentiles }} \\
\hline & \multirow{2}{*}{$\begin{array}{l}\text { Verbal } \\
\text { recall }\end{array}$} & \multirow{2}{*}{$\begin{array}{l}\text { Visual } \\
\text { recall }\end{array}$} & \multirow{2}{*}{$\begin{array}{l}\text { Verbal } \\
\text { recog }\end{array}$} & \multirow{2}{*}{$\begin{array}{l}\text { Visual } \\
\text { recog }\end{array}$} & & \\
\hline & & & & & Recall & Recog \\
\hline A.B. & 3 & 11 & 14 & 9 & $<1.0$ & 1.0 \\
\hline L.J. & 1 & 5 & 13 & 14 & $<1.0$ & 2.3 \\
\hline P.H. & 0 & 3 & 9 & 10 & $<1.0$ & 1.0 \\
\hline P.N. & 0 & 4 & 6 & 10 & $<1.0$ & $\leq 1.0$ \\
\hline R.C. & 2 & 8 & 15 & 8 & 5.1 & 15.9 \\
\hline J.W. & 3 & 6 & 14 & 8 & $<1.0$ & 1.0 \\
\hline Control mean & 19.2 & 30.7 & 18.0 & 18.0 & 34.2 & 61.4 \\
\hline
\end{tabular}

*Note. The maximum raw score was 36 for each recall test and 24 for each recognition test. On the two recognition tests, a raw score of 6 represents chance performance. Recog, recognition.

of their observations of three individuals who became amnesic early in life as the result of damage thought to be limited to the hippocampal region. They proposed that these patients could perform well on recognition tests because the damage did not extend to the perirhinal and entorhinal cortices. One of their patients (Jon), performed normally on the recognition portion of the Doors and People Test as a young adult, despite a severe impairment on the recall portion.

Our findings with the Doors and People Test contrast with the findings for Jon. There seem to be three ways to understand this difference. First, damage to the hippocampal region in early life

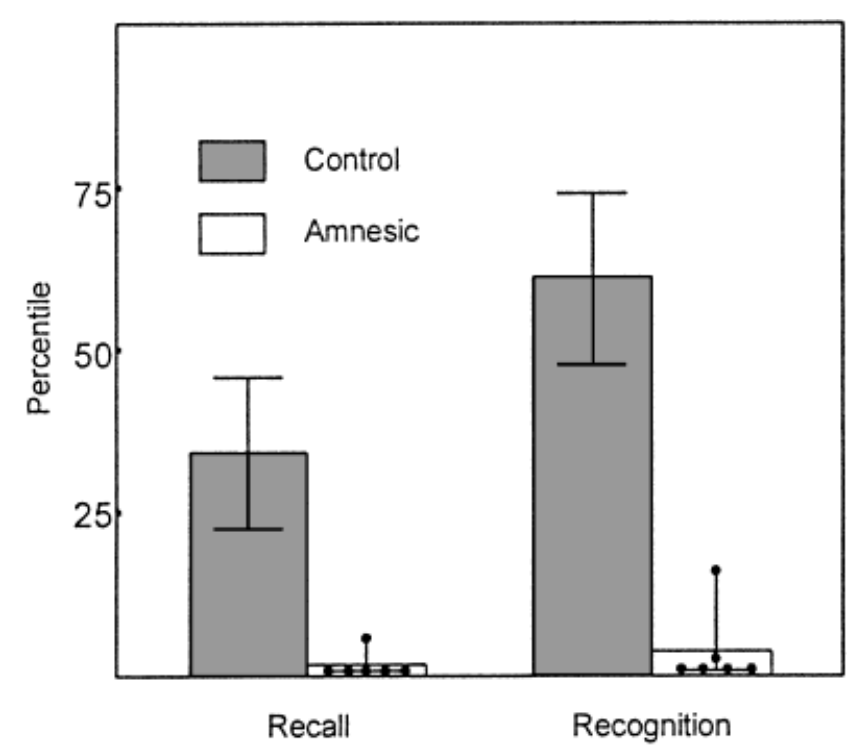

FIGURE 2. Mean percentile scores for controls $(n=6)$ and amnesic patients $(n=6)$ for recall and recognition. Percentile scores calculated as less than or equal to $\mathbf{1 . 0}$ were plotted here as $\mathbf{1 . 0}$ (five cases for recall, four cases for recognition). For controls, brackets show SEM. For the amnesic patients, the individual scores are indicated by circles. might somehow allow cortical areas adjacent to the hippocampus to assume some of its functions. Second, as he grew up, Jon may have developed strategies that enabled him to compensate to some extent for his memory impairment. Perhaps it is easier to compensate for impaired recognition impairment than impaired recall. Third, Jon's lesion may be different in some way than the lesions in our patients. Although the resolution of MR images is not sufficient to address this issue definitively, Jon's lesion and the lesion in our patients P.H. and L.J. seem rather similar. In none of the cases were there indications of damage to the entorhinal, perirhinal, or parahippocampal cortices that lie adjacent to the hippocampus. Furthermore, we estimated that the volume of Jon's hippocampal region is reduced by $46 \%$ (from Fig. 3 of VarghaKhadem et al., 1997). For L.J. and P.H., these values are 34\% and $22 \%$, respectively (estimated from areal calculations of the hippocampus, dentate gyrus, and subiculum).

The Doors and People Test allows the calculation of a percentile score for the discrepancy between recognition and recall performance. We could not obtain an accurate estimate of the discrepancy score because the scaled scores of many of our patients on the recall portion of the test fell below the range for which the testing manual provided normative data. To estimate a discrepancy score in these cases, the patients were assigned the lowest possible scaled score (scaled score $=1)$. This approach had the effect of increasing the discrepancy score for recall and recognition performance. Nevertheless, the resulting percentile discrepancy scores were similar for amnesic patients and controls $(33 \%$ and $30.6 \%$, respectively).

In summary, we have evaluated the performance of amnesic patients, including three patients with damage thought to be limited to the hippocampal region, on the Doors and People Test. Our finding of impaired performance contrasts with the good performance on this same test by the patient Jon, who became memory-impaired early in life. We suggest that Jon's good recognition memory performance may depend on compensation for his early injury having occurred during development, either as 
a result of functional reorganization of cortical areas adjacent to the hippocampus, or as a result of learned strategies.

\section{Acknowledgment}

We thank Joyce Zouzounis for assistance.

\section{REFERENCES}

Aggleton JP, Brown MW. 1999. Episodic memory, amnesia, and the hippocampal-anterior thalamic axis. Behav Brain Sci 22:425-490.

Aggleton J, Shaw C. 1996. Amnesia and recognition memory: a re-analysis of psychometric data. Neuropsychologia 34:51-62.

Baddeley AD, Emslie H, Nimmo-Smith I. 1994. Doors and people: a test of visual and verbal recall and recognition. Bury St. Edmunds, England: Thames Valley Test Co.

Gabrieli JDE. 1998. Cognitive neuroscience of human memory. Annu Rev Psychol 49:87-115.

Gilbert J, Levee R, Catalano K. 1968. A preliminary report on a new memory scale. Percept Mot Skills 27:277-278.

Haist F, Shimamura AP, Squire LR. 1992. On the relationship between recall and recognition memory. J Exp Psychol Learn Mem Cog 18:691-702.

Kaplan EF, Goodglass H, Weintraub S. 1983. The Boston naming test. Philadelphia: Lea Febiger.
Mattis S. 1976. Dementia Rating Scale. In Bellack R, Keraso B, editors. Geriatric psychiatry X. New York; Grune and Stratton. p 77-121.

Polich J, Squire LR. 1993. P300 from amnesic patients with bilateral hippocampal lesions. Electroencephalogr Clin Neurophysiol 86:408417.

Reed JM, Squire LR. 1997. Impaired recognition memory in patients with lesions limited to the hippocampal formation. Behav Neurosci 111:667-675.

Reed JM, Squire LR. 1998. Retrograde amnesia for facts and events: findings from four new cases. J Neurosci 18:3943-3954.

Schacter DL, Tulving E, editors. 1994. Memory systems 1994. Cambridge, MA: MIT Press.

Shimamura AP, Jernigan TL, Squire LR. 1988. Korsakoffs syndrome: radiological (CT) findings and neuropsychological correlates. J Neurosci 8:4400-4410.

Squire LR, Zola S. 1997. Amnesia, memory, and brain systems. Philos Trans R Soc Lond B 352:1663-1673.

Squire LR, Amaral DG, Press GA. 1990. Magnetic resonance measurements of hippocampal formation and mammillary nuclei distinguish medial temporal lobe and diencephalic amnesia. J Neurosci 10:31063117.

Vargha-Khadem F, Gadian DG, Watkins KE, et al. 1997. Differential effects of early hippocampal pathology on episodic and semantic memory. Science 277:376

Vargha-Khadem F, Watkins KE, Baddeley AD, et al. 1998. Dissociation between recognition and recall after early hippocampal damage. $S$ Neurosci Abstr 24:1523.

Zola S, Squire LR. The medial temporal lobe and the hippocampus. In Tulving E, Craik FIM, editors. The Oxford handbook of memory. New York: Oxford University Press (in press). 